\title{
La narración periodística como estrategia de formación ciudadana en Prensa Escuela*
}

\author{
Journalistic Narration as a Strategy for Citizen Formation in the School Press \\ A narração jornalística como estratégia de formação cidadã em Prensa Escuela (Imprensa Escola)
}

Carolina Campuzano Baena ${ }^{\mathrm{a}}$

Universidad Pontificia Bolivariana, Colombia

carolina.campuzano@upb.edu.co

ORCID: http://orcid.org/0000-0002-7495-3336

Sonia Amparo Guerrero Cabrera

Universidad de San Buenaventura, Colombia

ORCID: http://orcid.org/0000-0001-9176-0029
DOI: https://doi.org/10.11144/Javeriana.syp38-75.npef

Fecha de recepción: 02 Octubre 2018

Fecha de aprobación: 25 Mayo 2019

Fecha de publicación: 15 Noviembre 2019

\section{Resumen:}

En este artículo, se exponen los principales hallazgos de la investigación "La mediación de Prensa Escuela en la formación ciudadana y la ética”, realizada por Prensa Escuela, Programa ejecutado en convenio con las universidades Pontificia Bolivariana, San Buenaventura y el periódico El Colombiano de Medellín. Bajo una metodología cualitativa y de revisión documental, se sistematizaron los escritos que componen la publicación anual de El Taller (2012-2016) y a través de un análisis hermenéutico se pudo establecer cómo la narración, desde los géneros periodísticos, ha sido una estrategia significativa para la formación de jóvenes en ciudadanía. Se encuentra que se fortaleció el pensamiento crítico, la imaginación narrativa y la empatía con el otro, así como la construcción de su identidad y la conciencia sobre la responsabilidad que tienen como actores de la historia al participar por medio de la palabra y no solamente como espectadores de acontecimientos.

Palabras clave: narración, formación, ciudadanía, educación, comunicación.

\section{Abstract:}

This article expounds the main findings in the research "The Mediation of the School Press in the Citizen Formation and the Ethics", which was conducted by Prensa Escuela [School Press], a program carried out as a covenant between the colleges Pontificia Bolivariana, Universidad San Buenaventura and the newspaper El Colombiano from Medellín. Using a qualitative methodology with document review, the writings produced for the annual publications of El Taller (2012-2016) were systematized. Then a hermeneutic analysis allowed seeing how the narration, with journalistic genres, has been a significant strategy for the formation of the youth in citizen's issues. It was found that the critical thinking, the narrative imagination and the empathy with others are strengthened. This strategy also reinforces the construction of the youth identity and the awareness of their responsibility as actors of the history, by participating with their words and not only as spectators of the events.

Keywords: narration, formation, citizenship, education, communication, UNESCO thesaurus.

\section{Resumo:}

Neste artigo, expõem-se os principais achados da pesquisa "A mediação de Prensa Escuela na formação cidadã e a ética", realizada por Prensa Escuela, programa executado em convênio com as universidades Pontifícia Bolivariana, San Buenaventura e o jornal El Colombiano de Medellín. Com metodologia qualitativa e de revisão documental, sistematizaram-se os escritos que compõem a publicação anual de El Taller (2012-2016) e através de análise hermenêutica foi possível estabelecer como a narração, desde os géneros jornalísticos, já foi uma estratégia significativa para a formação de jovens na cidadania. Descobriu-se que o pensamento crítico, a imaginação narrativa e a empatia com o outro foram fortalecidos, bem como a construção da identidade e a consciência da responsabilidade que eles têm como atores da história ao participar através da palavra e não apenas como visualizadores de eventos. Palavras-chave: narração, formação, cidadania, educação, comunicação, tesauros da UNESCO.

Notas de autor:

a Autora de correspondencia. Correo electrónico: carolina.campuzano@upb.edu.co 


\section{Introducción}

Prensa Escuela es un programa que busca que los jóvenes, a través de la lectura crítica de textos y de la realidad, así como la producción de contenidos y la narración de historias con responsabilidad, puedan formarse en ciudadanía. Este programa lo realiza, desde el año 1994, el periódico El Colombiano en convenio con la Universidad Pontificia Bolivariana y la Universidad de San Buenaventura (Medellín), principalmente en contextos educativos del Área Metropolitana del Valle de Aburrá, en el departamento de Antioquia. Para alcanzar los objetivos mencionados, el programa realiza actividades de investigación que, como en este caso, permitan identificar si en su trayectoria, ha logrado que los estudiantes participantes de los talleres de formación en lectura y escritura, desde los géneros periodísticos y la información de actualidad, han adquirido habilidades ciudadanas.

En este artículo, fruto de la investigación denominada "La mediación de Prensa Escuela en la formación de ciudadanía y la ética”, se pretende mostrar cómo los participantes, a través de la elaboración de narraciones de sus vidas, de relatos sobre lo que acontece en sus contextos y de historias sobre sus experiencias, han construido aprendizajes para contribuir con la construcción una sociedad mejor, menos indiferente, más crítica y participativa.

Así, en esta investigación se hizo un análisis de tipo hermenéutico de las categorías ciudadanía y ética, en los textos publicados entre 2012 y 2016 en El Taller, un espacio en el cual el programa recoge anualmente las narraciones elaboradas por los estudiantes de diferentes instituciones educativas que participan en él como talleristas (estudiantes de las Universidades Pontificia Bolivariana y de San Buenaventura de los programas de Comunicación Social y Periodismo y licenciaturas) y alumnos de bachillerato que asisten voluntariamente.

\section{Metodología}

\section{Leer para comprender}

La investigación fue de corte cualitativo, metodología que parte del hallazgo de las cualidades que caracterizan una realidad y que además, produce datos descriptivos en contextos situacionales y estructurales donde se aceptan todos los procesos de creencias, mentalidades y saberes de los sujetos, como elementos de análisis; así, a partir de estos, se llega a un conocimiento que hable sobre la realidad humana, ya que "la investigación cualitativa trata de identificar la naturaleza profunda de las realidades, su estructura dinámica, aquella que da razón plena de su comportamiento y manifestaciones" (Martínez, 2006, p. 128).

Asimismo, se hizo un rastreo documental para recopilar y sistematizar los textos que se analizarían, y esclarecer, principalmente, los conceptos de formación ciudadana y ética, buscando la "captación por parte del investigador de datos aparentemente desconectados, con el fin de que a través del análisis crítico se [construyeran] procesos coherentes de aprehensión del fenómeno y de abstracción discursiva del mismo, para así valorar o apreciar nuevas circunstancias" (Botero, 2003, p. 111), lo que permitió elaborar una matriz para el análisis hermenéutico. Esta metodología posibilita una interpretación de la realidad, para dilucidar la multiplicidad de significados de los textos y su sentido. De este modo, se buscó revisar y entender la configuración de las categorías formación ciudadana y ética dentro de las producciones mencionadas, sin olvidar el contexto del cual hacen parte, tal como lo enunciara Martínez (2002).

La hermenéutica tendría como misión descubrir los significados de las cosas, interpretar lo mejor posible las palabras, los escritos, los textos, los gestos y, en general, el comportamiento humano, así como cualquier acto u obra suya, pero conservando su singularidad en el contexto de que forma parte. (p. 2) 


\section{Comunicación y educación, una apuesta para la ciudadanía}

Para Prensa Escuela existen dos conceptos clave que marcan su quehacer como programa de formación: comunicación y educación. Por eso, sus fundamentos pedagógicos se basan en la propuesta de Celestin Freinet, pedagogo francés, que a principios del siglo XX, introdujo el periódico escolar como un recurso para mejorar las actividades que los estudiantes realizaban en la escuela, procurando no solo dinamizar las clases, sino también que hubiera un aprendizaje significativo, el cual los motivara a ir más allá de la simple realización de tareas académicas; lo que va en consonancia con el objetivo de Prensa Escuela: lograr que los estudiantes narren las historias tanto de sus contextos como de sus propias vidas, reconociéndose como sujetos que tienen un papel activo y una responsabilidad en su entorno:

La propuesta del educador francés (Freinet) estaba focalizada en el alumno, su interés era ayudarlo a apropiarse de la palabra para que pudiera expresar su mundo, sus ideas y sus opiniones; [...] y los convirtió en productores de unos contenidos que compartían con las comunidades más cercanas y luego con otras ubicadas en diferentes regiones de Francia y del mundo. (Ceballos, 2015, p. 20)

De esta manera, se busca que los estudiantes aprendan a nombrar su mundo, pues, y conectando con Paulo Freire (1985), que "el sentido básico de la alfabetización sea aprender a escribir su vida como autor y testigo de su historia: biografiarse, existenciarse, historizarse" (p. 7).

Ahora bien, aunque la ciudadanía es un concepto que se ha construido por un proceso histórico- social, este se ha entendido, principalmente, desde dos puntos de vista: como un estatus legal o como una práctica (Bárcena, Gil y Jover, 1999). Tomando esta última definición, para Prensa Escuela el ejercicio de la ciudadanía no se limita a cumplir, por ejemplo, con unos estatutos jurídicos como hacer parte de un territorio o tener una mayoría de edad, sino como una forma de relación entre las personas donde prime la convivencia con el otro en pro del bien común, es decir, entiende este concepto como una práctica donde es clave la empatía, la solidaridad y el uso del diálogo para resolver dificultades. En la ciudanía, se reconoce al sujeto como un ser político que además está configurado por una cultura, tal como lo dijera Aristóteles en su obra Política.

Así como el marino es un miembro de una comunidad, así también lo decimos del ciudadano. Aunque los marinos son desiguales en cuanto a su función (uno es remero, otro piloto, otro vigía y otro tiene otra denominación semejante), es evidente que la definición más exacta de cada uno será propia de su función, pero al mismo tiempo una cierta definición común se adaptará a todos. La seguridad de la navegación es, en efecto, obra de todos ellos, pues a este fin aspira cada uno de los marinos. Igualmente ocurre con los ciudadanos; aunque sean desiguales, su tarea es la seguridad de la comunidad.

De este modo, para Prensa Escuela la ciudadanía no se limita a una concepción jurídico-política de pertenencia a un territorio determinado. Entonces, siguiendo a Cubides (1998) quien recuerda a Bárcena, la ciudadanía es:

[...] una práctica comprometida en lo público, y en la formación de virtudes correspondientes; la comunidad sería la fuente de valores, deberes y virtudes, y no los derechos individuales que los liberales confieren desde una visión abstracta del yo y de la humanidad. (p. 42)

Por eso, a través de los talleres, Prensa Escuela ha buscado que los jóvenes de distintos estratos socioeconómicos adquieran habilidades comunicativas con las que, además, se formen en la ciudadanía como una práctica en la que el reconocimiento del otro, la formación de la identidad y el pensamiento crítico estén presentes, pues, como dice Gumucio (2006), aunque estar informado sea un requisito fundamental para ejercer la ciudadanía, lo es aún más la comunicación. Todo esto pensando en que, como dice Maiztegui (2007):

El principal objetivo de la formación ciudadana es fomentar los valores y conocimientos necesarios para desarrollarse en la vida pública y colaborar en un posible cambio social; ayuda a creer en el espíritu crítico y transformador, que propicia la práctica de los derechos y los deberes ciudadanos. (p. 2) 


\section{La narración como estrategia de formación}

En el Programa, se trabaja principalmente con los géneros periodísticos narrativos que propician el encuentro con el otro y sus historias, la observación e interpretación del entorno y la reconstrucción de acontecimientos, experiencias o momentos vividos. Para esto, cada año en las sesiones de trabajo con los jóvenes de las instituciones educativas, se utiliza la metodología taller, a través de la cual, por medio de actividades didácticas acompañadas de un tallerista guía, cada estudiante pueda conocer las principales características de la entrevista, la crónica, el perfil y la fotografía y hacer uso de estos para narrar sus realidades.

Es clave aclarar que en cada taller hay un encuentro con la realidad, pues para el programa la información y el conocimiento de lo que sucede en un territorio es trascendental para la toma de decisiones, con el fin de no ser indiferentes y realizar acciones de cambio en las comunidades; por esto, se promueve la lectura de prensa, de modo que desde la juventud, los estudiantes se interesen por conocer lo que sucede a su alrededor y manifiesten sus vivencias, las historias de los personajes de sus barrios y los relatos que van construyendo en su paso por el mundo.

Uno ve mucho en la televisión que desplazaron gente, y mientras está pequeño uno no se da cuenta de lo grave que es ni del dolor, y de lo duro que es hasta que le pasa, eso es como una puñalada. (Herrón, 2013, p. 19)

Lo anterior es un ejemplo de los textos que aparecen en la publicación anual del programa y que se analizaron en esta investigación, se evidencia cómo la narración hace de los estudiantes no simples espectadores, sino partícipes de la historia. Ahora, siguiendo esta línea, y como dice Cubides (1998, p. 46):

La ciudadanía-consumo requiere el desarrollo de comunidades interpretativas, capaces de una recepción crítica de los medios y de la contextualización de los mensajes transmitidos; lugar en el que puede operar una noción de educación que va más allá del ámbito de la escuela, y que la inscriba en el ecosistema comunicativo general.

Por esto, el programa ha hecho énfasis en la exploración de los géneros periodísticos (especialmente la entrevista, la crónica y el perfil) y del uso de la prensa como recurso didáctico en los talleres, pues se considera que estos al estar anclados a la realidad para hacer sus construcciones discursivas, permiten que los individuos desarrollen una conciencia crítica, ya que para hacer un relato desde el periodismo se debe hacer uso de las herramientas de reportería que facilitan el acercamiento al otro (al que es distinto), hacerse preguntas, investigar para responder esos interrogantes y luego escribir o narrar teniendo en cuenta los distintos datos que reconstruyan la información, siendo conscientes de que lo que se publique va a ser leído, por lo que esto implica un alto grado de responsabilidad y compromiso.

Además, para Prensa Escuela, concordando con las palabras de Martín-Barbero (2012), citado por Omar Rincón (2012), el tipo de periodismo que necesita Colombia es aquel en el que se reflejen relatos para comprender lo que está pasando, donde haya análisis y contextualizaciones históricas y sociales; un periodismo que "eduque en el debate de las ideas y las ciudadanías, que niegue el insulto y el odio como modo de argumentar, que documente que no hay una sola manera de ser ciudadanos y que acabe con el cuento del bueno y el malo para ganar sentido crítico" (2012, párr. 16).

Así se da relevancia al entorno inmediato, pues es clave que los estudiantes aprendan a encontrar en lo cotidiano historias que reivindiquen el valor de lo “infraordinario" como lo diría George Perec (2008) para interrogarlo, describirlo e intervenirlo.

Apostado en la orilla de una calle empinada que va de Ancón hacia Pueblo Viejo en el municipio de La Estrella, está él, un anciano de tez trigueña y de baja estatura. Siempre ahí. En la mañana, en la tarde y aunque tiene un taburete desvencijado para mitigar cansancios, se le ve más de pie que sentado. Vestido pobremente pero con la elegancia que brota de su dignidad humilde, que no requiere marcas ni modas, acompaña su atuendo con una gorra que lejos de vanidades juveniles, espanta soles y le procura alguna sombra. (Cadavid, 2012, p. 27) 
Como se ve en este relato y como se seguirá mostrando más adelante, narrar a través de los géneros periodísticos mencionados, logra desarrollar en el sujeto una de las habilidades básicas para la ciudadanía que describe Martha Nussbaum (2015): la imaginación narrativa, que se puede traducir como empatía.

Aprender a ver a otro ser humano no como una cosa sino como una persona completa, no es un logro automático: debe ser promovido por una educación que refine la capacidad de pensar acerca de lo que puede ser la vida interna de otro y también para entender por qué no es posible captar plenamente ese mundo interior, por qué una persona es siempre hasta cierto punto un enigma para el otro. (párr. 35)

Dentro del programa se fomenta también el uso de la primera persona al escribir, ya que se están narrando las experiencias vividas por los mismos estudiantes, y que dan cuenta de su paso por el mundo, de una manera de ser colombianos, como diría Jesús Martín-Barbero (2012). Dichos textos muestran la capacidad de autocrítica y de problematización de la realidad que hacen los jóvenes cuando cuentan sus propias anécdotas en El Taller, dos de las características que tiene la ciudadanía como práctica y que se evidenciaron al analizar los relatos.

Mi aprendizaje en Prensa Escuela empieza por darme cuenta de mi papel, que es precisamente el de aprender. Aprendí a tener los ojos bien abiertos. Nada de lo que pasa a nuestro alrededor es gratuito. Todo lo que vemos es una causa y un efecto; desde un niño corriendo en la calle de un barrio de Medellín, hasta el color verde de los árboles de la ciudad. Y todos tenemos el poder de ver estos detalles. (Chamat, 2012, p. 21)

Además, como dice Valderrama (2007), la narración es fundamental en la construcción de identidades, para el reconocimiento propio y del otro: "la ciudadanía es también una identidad; la expresión de la pertenencia a una comunidad política, una cultura compartida" (Cubides, 1998, p. 43), y esta, aunque es construida individualmente, no se puede olvidar que ese individuo interactúa con otros y está en el marco de una comunidad.

Ahora, volviendo a Jesús Martín-Barbero, “no existe identidad sin narración” (2009, p. 178), pues es la narración de historias la que permite considerar al otro, ser tenidos en cuenta en las decisiones que nos afectan y así pertenecer a una comunidad política. Por las anteriores razones, es que el autor rescata la significativa polisemia que tiene el verbo contar y su función en la construcción de país. Igualmente, Taylor (1996 citado por Bárcena, 1997) dice que la construcción de la identidad se da en forma de relato, ya que somos "lo que somos por lo que hemos llegado a ser, por la narración del cómo llegamos a ser” (p. 91).

Entonces, en Prensa Escuela, se ofrece un espacio formativo en el cual "la educación no es un simple aprendizaje sino una experiencia múltiple, en donde es indispensable el diálogo para favorecer el pluralismo de las convicciones, la promoción de los desacuerdos racionales y el ejercicio de diversas prácticas sociales" (Cubides, 1998, p. 45), así la escucha, la conversación y la discusión con argumentos son actividades imprescindibles para ir forjando la capacidad crítica y el respeto, en los jóvenes.

\section{Hallazgos: Los géneros periodísticos en la construcción de ciudadanía}

A continuación, a través de tres géneros periodísticos, se evidencian las características de la formación ciudadana en Prensa Escuela.

\section{La entrevista}

Este género permite acercarse al otro con la disposición de escucharlo y entablar una conversación donde se pueda obtener información específica que enriquezca el reconocimiento de un tema, situación o personaje. Los participantes usan la entrevista tanto como herramienta como un género en sí mismo en el que narran al otro, problematizan la realidad y se interrogan sobre los acontecimientos, para trascender la comprensión inicial frente a un hecho o una persona. Por ejemplo, una de las entrevistas publicadas en El Taller, llevada a 
cabo por una maestra, deja ver su asombro por las respuestas que le daba un estudiante; ella pudo reconocer lo valioso de este joven que, a pesar de vivir en un barrio con dificultades y tener bajos recursos, era un campeón de judo y a la vez un alumno que no descuidaba las labores en el colegio.

Así termina la entrevista. Cada uno continúa su rutina, pero el diálogo con Alexander Borja sigue en mi cabeza porque él es un muchacho de bajos recursos del barrio La Sierra, un lugar conocido por sus conflictos y porque sus habitantes viven entre el fuego cruzado; pero nuestro deportista es respetuoso, amigable, buen estudiante y me pregunto cómo es posible que en sus condiciones logre destacarse deportivamente sin afectar su rendimiento académico, cuando otros jóvenes tal vez, con mejores condiciones, se descuidan a tal punto de que no responden ni siquiera con sus compromisos académicos [...]. (Meléndez, 2012, p. 15)

Aunque el rol de la autora de este relato era ser docente, en Prensa Escuela volvió a ser estudiante y puedo reconocer y valorar a uno de sus alumnos no como un sujeto vacío de conocimientos sino como un ser humano complejo. Así, como diría el periodista norteamericano Gay Talese, "cuando tú entrevistas a otros colombianos los conviertes en historiadores de tu propio tiempo, aprendes a través de ellos acerca de la nación que es Colombia" (Talese, 2015, citado por Malagón, 2015, párr. 5).

Se ve, entonces, cómo los textos que se construyen para ser publicados en un medio como El Taller de Prensa Escuela "promueven procesos simbólicos que le permiten a la gente designar y expresar el mundo en sus propios términos” (Rodríguez, 2010, p. 4); esto es fundamental, porque los estudiantes hacen un uso del lenguaje que no consiste únicamente en reflejar una realidad, sino que permite intervenirla. Esto es:

El lenguaje, planteamos, no es una herramienta pasiva que nos permite describir cómo son las cosas. El lenguaje es activo, por medio de él participamos en el proceso continuo del devenir [...]. Modelamos nuestra identidad y el mundo en que vivimos, a través del lenguaje. [...] La identidad personal, la nuestra y la de los demás, es un fenómeno estrictamente lingüístico, una construcción lingüística. Lo mismo sucede con el mundo en que vivimos. Poblado de entidades, relaciones, acciones y eventos, nuestro mundo se constituye en el lenguaje. (Echeverría, 2003, p. 23)

Así, al narrar desde los géneros periodísticos, en este caso desde la entrevista, los jóvenes están aprehendiendo uno de los pilares de la ciudadanía, nombrar y nombrarse para construir su identidad y la de los demás al hacerlos existir por medio del lenguaje.

\section{La crónica}

Es conocida como el Ornitorrinco de la prosa porque esta se "beneficia de muchos géneros: tiene algo del relato, del reportaje, del ensayo, incluso del teatro por el manejo de los diálogos” (Villoro, 2012, párr. 4). Esta forma de narrar es una de las más utilizadas en El Taller, pues permite recrear escenarios, personas y momentos que han vivido los estudiantes. Este género periodístico, ha permitido que los jóvenes se reconozcan como personas que tienen voz propia, que dejen de mirar su mundo como una naturaleza muerta en la que no acontece nada y sean capaces de reflexionar sobre lo que les ha sucedido, de descubrir que tienen cosas por decir, que pueden participar a través de la palabra y usar todos los sentidos para reconstruir sus realidades, ya sea de lo vivido en el colegio, el barrio o la ciudad. Entonces, quien participa de Prensa Escuela,

[...] al comenzar a escribir libremente no copia palabras, sino que expresa juicios. Estos, de cierta manera, intentan reproducir el movimiento de su propia experiencia; el alfabetizando, al darles forma escrita, va asumiendo gradualmente la conciencia de ser testigo de una historia de que se sabe autor. En la medida en que se percibe testigo de su historia, su conciencia se hace reflexivamente más responsable de esa historia. (Freire, 1985, p. 7)

De esta manera, en los diversos relatos construidos por los estudiantes, se encuentra cómo estos jóvenes, que están en su mayoría entre los 13 y 17 años de edad, van adquiriendo una conciencia gradual del mundo que habitan: al escoger el tema e investigarlo, los participantes se dan cuenta de que van construyendo su historia, tejiendo los hilos de las versiones de quienes lo habitan y rescatando realidades que, de otro modo, 
no serían contadas. El siguiente párrafo hace parte de uno de los textos publicados en 2012 en El Taller, y es una muestra de lo anteriormente dicho.

“Desde 1990 vivo en 'La Curva del Diablo'. Se llama así porque el día en que Pablo Escobar murió hubo unas 20 muertes en ese lugar; eso es todo un mito, así como la 'transformación' de Moravia. En 1998, empezaron los reasentamientos, no reubicaciones, reasentados, ¿sí sabe la diferencia? Los reubicados son los que se van para otro lugar y los reasentados son ubicados en el mismo territorio o muy cerca”, dice esta Zarahí Mazo. (Lima, 2012, p. 24)

En este punto, es clave mencionar que en Prensa Escuela la narración no se limita a lo que les pasa a los estudiantes en su colegio, es decir, lo textos producidos no se hacen pensando en la publicación institucional de un colegio, sino que reconoce a esas personas como seres que habitan el mundo y están permeadas de mensajes que les llegan más allá del colegio, desde sus familias, los medios de comunicación o los acontecimientos que han visto y vivido en la calle.

A través de la crónica, los estudiantes tienen que investigar, esto es: observar, plantear un tema del que quieran hablar, sopesar con sus talleristas y compañeros la pertinencia de ese tema, ser conscientes de la responsabilidad que implica construir una historia que va a ser publicada, elaborar argumentos que sustenten la relevancia del contenido del artículo y poner los suficientes detalles, datos o cifras que le den su carácter de rigurosidad periodística cuando se narra la realidad, especialmente en este género, en el que hay que usar todos los sentidos para reconstruir escenarios, estar atentos a lo que el otro narra para contrapreguntar y así darle verosimilitud a la historia. En este proceso formativo, es clave conocer que, como dice Kaplún (2002):

[...] Lo que el sujeto educando necesita no es sólo (sic) ni únicamente datos, informaciones, sino instrumentos para pensar, para interrelacionar un hecho con otro y sacar consecuencias y conclusiones para construirse una explicación global, una cosmovisión coherente. [...] sólo (sic) participando, involucrándose, investigando, haciéndose preguntas y buscando respuestas, problematizando y problematizándose, se llega realmente al conocimiento. Se aprende de verdad lo que se vive, lo que se recrea, lo que se reinventa y no lo que simplemente se lee y se escucha. (p. 46)

Lograr todo eso implica que los talleristas acompañen a los estudiantes mostrándoles la importancia de no dejar pasar desapercibida la cotidianidad, por ejemplo en el texto "De infarto moriremos", una estudiante del grado noveno logra recrear desde cada detalle un momento significativo para ella: la final del equipo de fútbol que ella ama, pasión que comparte de su padre. Allí no habla solo de sus gustos, sino que refleja una parte de la cultura donde se describen los ritos y costumbres que se dan en dicho deporte y también las prácticas familiares en torno a este juego. Eso muestra que Catalina, al construir su crónica, logra expresar y valorar la cultura y también toma conciencia sobre su propia identidad.

A las 5:55 p. m. salieron los equipos, se soltaron los extintores y los hinchas levantaron el plástico para formar el 'tifo' que decía "vamos poderoso DIM". Mi piel se erizó y mis ojos se pusieron más llorosos. ¡Estábamos a 90 minutos de la gloria! Sonó el himno de Colombia y luego el de Antioquia, lo cantamos con orgullo de nuestro país y de nuestro departamento. Todo el estadio cantó a pulmón, y aunque se terminó la primera estrofa, la gente continúo con la segunda, dejando en alto el himno del pueblo. Los jugadores del Medellín se pararon en la mitad de la cancha y aplaudieron a su hermosa afición, en ese momento pensé: "no son once, somos miles". (González, 2016, p. 12)

La construcción de estas crónicas se da durante el proceso de formación en el cual los estudiantes reconocen las principales características de este género y también leen varios textos que han escrito otros participantes en El Taller, pues esta publicación también se convierte en una herramienta pedagógica. Se constituye también en referente para que los jóvenes se motiven a la escritura, actividad frente a la cual algunos muestran resistencia, pero cuando ven cómo esta constituye en la posibilidad de darles la palabra para que otros los lean, es decir, que da visibilidad al sujeto social, se animan a proponer temas y a contar sobre lo que les interesa. Como dice Rodríguez (2010) la lucha por el derecho a la comunicación es fundamental, aunque un reto, porque esta implica que las comunidades puedan expresar sus propias versiones de la realidad, lo cual se ve en la siguiente historia publicada en El Taller en el año 2013. 
Soledad es un municipio del Atlántico muy cercano a Barranquilla y hace parte de su área metropolitana. Su gente es carismática y alegre, como toda población tiene manifestaciones culturales que la distinguen de las demás. [...]. "El merecumbé es el baile típico de Soledad y todos lo bailamos, su vestuario es muy colorido, el de la mujer lleva una falda por debajo de la rodilla y una blusa estilo corsé con encaje y adornada con notas musicales, y el del hombre es un pantalón largo, camisa manga larga tipo liquilique y un sombrero, todo va decorado con notas musicales", me explicó Dayan con alegría. (Torres, 2013, p. 14)

Este escrito es una muestra de cómo, por medio de los géneros periodísticos, esta estudiante se dejó sorprender por un territorio y empezó a narrarlo para entenderlo, es decir, con la reportería. Esta joven está haciendo un reconocimiento de los valores, creencias y reglas de una comunidad, como lo es la de Soledad, con lo cual no solo está valorando esa cultura, sino que está desarrollando una de sus habilidades como ciudadana, ya que como dice Nussbaum (2005, citada por Beuchat, 2016): "el ciudadano del mundo es una persona con un gran desarrollo de pensamiento crítico; es éticamente sensible y empático" (p. 108).

Ahora, como dice Martín-Barbero citado por Rodríguez (2010), si la posibilidad de ejercer la ciudadanía está estrechamente relacionada con la de que haya gente que aprenda a contar su propia historia, aquí se está poniendo en práctica la ciudadanía, "es decir es que la capacidad de narrar, el hecho mismo de nombrar al mundo, de tejer nuestras propias versiones de la vida, tiene que ver con la fuerza política para moldear el entorno" (p. 10).

Toda esta construcción de un texto que se piensa para ser publicado y, por tanto, leído y compartido por otros, expone a los estudiantes a adquirir un pensamiento crítico, puesto que en El Taller se discute con los otros sobre las ideas que se tiene; así, volviendo a Nussbaum (2015, párr. 28):

Los estudiantes expuestos a la instrucción en pensamiento crítico aprenden, al mismo tiempo, una nueva actitud frente a los que no concuerdan con ellos. Aprenden a ver a quienes no están de acuerdo no como enemigos a (sic) ser derrotados, sino en cambio, como personas que tienen razones para lo que piensan.

\section{El perfil}

Por medio de este género, los participantes de Prensa Escuela se acercan a una persona para reconocerla desde distintas facetas de su vida: en su labor, en sus anécdotas, en sus sueños y fracasos. Este género, como dice la periodista argentina Leila Guerriero en entrevista a Mauro Libertella (2015), permite reconocer que nadie es monolítico, trata de humanizar y acercar a gente aparentemente lejana, a través de diálogos y opiniones de otros, evitando caer en estereotipos o juzgar, y usando pequeñas anécdotas que permitan profundizar en el alma de aquel del cual se está contando una historia.

En los textos de este género, escritos por los participantes de El Taller, se evidencia un reconocimiento del otro en su particularidad, un afán por narrar a aquel personaje del barrio que se ve todos los días, y que si no fuera por el impulso recibido en Prensa Escuela para convertir lo infraordinario en extraordinario, en digno de ser narrado, pasaría desapercibido al volverse parte del paisaje y de la rutina. Así, por ejemplo, se encuentran perfiles escritos por los talleristas como el siguiente:

Si va caminando por la calle y se encuentra a un hombre motilando a alguien en una acera, no se sorprenda, es Mario Hernández y su barbería en bicicleta. ¿Usted se dejaría motilar en la calle por un barbero con mucha experiencia? [...]. Este humilde y simpático hombre de contextura delgada y baja estatura tiene el cabello negro y lacio en el que destellan unas cuantas canas. En su rostro moreno, se dibujan algunas arrugas muy cerca de sus ojos pequeños. Sus grandes orejas son el marco de una nariz achatada que le sirve de techo a un vistoso y largo bigote blanco que no puede pasar inadvertido. (Tascón, 2012, p. 20)

Es importante recalcar que en este tipo de textos vuelve a aparecer una de las claves de la formación en ciudadanía enunciada por la filósofa estadounidense Martha Nussbaum: el desarrollo de la imaginación narrativa, lo que significa ser un lector de la historia de otra persona en aras de comprenderla. Este elemento se ve en el texto anterior, pero también en otros perfiles construidos por los jóvenes y publicados en El Taller, como el artículo "Chileno encontró el amor en Colombia", escrito en 2015 por K. Bedoya, estudiante del 
grado noveno, quien logra acercarse a un personaje de otro país y narrarlo con las características del perfil. Este ejemplo es relevante dentro de la investigación, pues muestra cómo esta participante al acercarse a un extranjero para conocer su historia, adquiere una característica clave del ciudadano democrático moderno, como menciona Nussbaum (2015): verse no solo como miembro de una nación, sino de un mundo que es heterogéneo y con diferencias y comprender las culturas de distintos países, su historia y tradiciones; un elemento vital en este mundo globalizado. Además, la imaginación narrativa permite el desarrollo de otra de las habilidades fundamentales para el ejercicio de la ciudadanía: el pensamiento crítico; por ejemplo, por medio de la narración de distintas historias se pueden consultar y confrontar fuentes y así verificar la información.

\section{Conclusiones}

Prensa Escuela, a través de El Taller, como forma de trabajo, ha logrado que los jóvenes participantes pongan en práctica y cultiven las habilidades ciudadanas: "la capacidad de pensar de manera crítica; la capacidad de trascender las lealtades locales y acercarse a los problemas mundiales como un 'ciudadano del mundo' y la capacidad de imaginar comprensivamente la situación del otro" (Nussbaum, 2015). Todo esto, al tener como eje en cada encuentro de formación la comunicación, es fundamental, pues como dice Gumucio (2006, p. 10):

La información no es en sí liberadora, ni siquiera lo es el conocimiento [...]. Hay problemas estructurales que la información no puede resolver, pero la comunicación sí, en la medida en que potencia las voces de los sujetos del desarrollo, fortalece sus organizaciones sociales, y facilita procesos de participación social a través del diálogo y del debate.

Las bases del programa son la información de actualidad, el diálogo y los relatos sobre la realidad, claves para la formación en ciudadanía, pues según plantean Bárcena et al. (1999, p. 150), en los procesos educativos debe primar el diálogo, la comunicación y la participación; además, se debe dar lugar a la explicación del contexto del territorio que se habita, así como el de otras culturas, entendiendo que no hay valores absolutos, sino distintas expresiones de costumbres que se han formado históricamente.

Ahora, para el programa "la ciudadanía es un mínimo de humanidad compartida" (Mockus, 2004, p. 11) y como menciona Ernani María Fiori en la introducción que hace a la Pedagogía del Oprimido de Paulo Freire: "el hombre se humaniza expresando y diciendo su mundo, ahí comienza la historia y la cultura [...] la palabra más que instrumento es origen de la comunicación, es diálogo, es lugar de encuentro" (2005, p. 25). Por eso, al propiciar el encuentro con el otro e impulsar la escritura de relatos, Prensa Escuela está permitiendo que los estudiantes obtengan ese mínimo de humanidad, con el que se pueda mantener viva la democracia, cumpliendo con lo que propone Mockus.

[...] el núcleo central para ser ciudadano es, entonces, pensar en el otro. Se basa en tener claro que siempre hay un otro, y tener presente no sólo (sic) al otro que está cerca y con quien sabemos que vamos a relacionarnos directamente, sino también considerar al otro más remoto, al ser humano aparentemente más lejano. (2004, p. 11)

Como se estableció a lo largo de este escrito, la narración tiene una relación muy cercana con la formación ciudadana. Al respecto, Valderrama (2007) indica cuatro componentes clave para el ejercicio ciudadano y que tienen relación con la comunicación: el diálogo, la narración, la hermenéutica y las dimensión tecnológica y mediática (p. 284). En Prensa Escuela todos estos elementos están presentes y se evidencian en los productos analizados.

Por ejemplo, y desglosando cada uno de esos términos, en Prensa Escuela cada sesión se presta para el diálogo, para conversar con el que es distinto, escucharlo y entenderlo, ya que se propician actividades en las que se reconozca a estos como "interlocutores válidos, con derecho a expresar sus intereses y a argumentarlos". Esto se evidencia cuando en los escritos de los estudiantes se percibe al otro como un ser que tiene algo que decir. Así, siguiendo a Fiori en la introducción a la Pedagogía del Oprimido de Freire (2005, p. 16), el 
sujeto busca nuevas palabras no para coleccionarlas en la memoria, sino para decir y escribir su mundo, su pensamiento, para contar su historia y ser consciente de que se es responsable de la historia.

La narración, por medio de los géneros periodísticos de la entrevista, la crónica y el perfil, busca romper con la tendencia, que enuncia Nussbaum (2015) de los sistemas de educación que tienden a pensar la formación solo con el objetivo de lograr el lucro nacional, convirtiendo a los sujetos en 'máquinas útiles'. Por el contrario, al darle la palabra al otro, al permitirle a los jóvenes la posibilidad de narrarse, se están generando "ciudadanos completos que puedan pensar por sí mismos, criticar la tradición y entender el significado de los sufrimientos y logros de otra persona" (párr. 3). Y en este acto de narración, también se da un proceso hermenéutico en el que el otro y la realidad son percibidos, analizados, interpretados y comprendidos por medio de un ejercicio comunicativo donde se decodifican prácticas, lenguajes y distintos aspectos de la realidad, gracias a que ese otro es entendido como un interlocutor válido con toda su carga cultural.

La propia realización humana se realiza en colaboración con los demás y a través de una acción compartida, de una acción comunicativa o de comunicación [...]. Somos animales narradores, dotados de palabra para contar historias y no simplemente voz. (Bárcena, 1997, p. 91)

Además, aunque en el programa no se trata de incorporar de manera mecánica los procesos pedagógicos, las tecnologías de la información y la comunicación, sí se le da la importancia a los medios de expresión con sus múltiples lenguajes y como objetos de conocimiento, donde El Taller se ha convertido en un espacio de expresión y diálogo con lo cotidiano, en el que los estudiantes ponen en juego su capacidad argumentativa y, en general, donde pueden adquirir competencias comunicativas para construir y poner a circular sentidos. Como dice Freinet (1974), "nuestra enseñanza ya no se centrará en la teoría intelectual escolástica, sino en el trabajo y la vida. Ahí reside precisamente la gran conquista pedagógica y humana de nuestras técnicas” ( $\mathrm{p}$. 141). En Prensa Escuela se "escribe para ser leídos".

Por último, vale la pena mencionar, como dice Francés (2008, citado por Contreras, 2017), la ciudadanía se define a partir del compromiso y la acción cotidiana, es decir, aunque en Prensa Escuela se han establecido pilares para que los participantes del programa adquieran algunas capacidades que les sirvan para ejercer la ciudadanía, esta es un proceso que se construye constantemente, no es un estatus que, al terminar la capacitación, se otorga al estudiante, no, pues "los ciudadanos son aquellas personas que asumen su ciudadanía mediante la participación en prácticas políticas cotidianas en tanto sujetos localizados cuya cotidianidad está cruzada por una serie de interacciones sociales y culturales” (Rodríguez, 2010, p. 4).

\section{Referencias}

Bárcena, F. (1997). El oficio de la ciudadanía. Barcelona: Paidós.

Bárcena, F., Gil, F., y Jover, G. (1999). La escuela de la ciudadanía. Bilbao: Desclée de Brouwer.

Bedoya, K. (2015). Chileno encontró el amor en Colombia. El Taller, 11, 19.

Beuchat, M. (2016). Formación ciudadana y autorregulación: conceptos claves para la práctica educativa. Revista Panamericana de Pedagogía. Saberes y Quehaceres del Pedagogo, 23, 95-116. Recuperado de https://dialnet.uni rioja.es/servlet/articulo?codigo $=5740974$

Botero, A. (2003). La metodología documental en la investigación jurídica: alcances y perspectivas. Opinión Jurídica, 2(4), 109-116. Recuperado de https://revistas.udem.edu.co/index.php/opinion/article/view/1350

Cadavid, R. (2012). Don Rodrigo, el agente de la curvita. El Taller, 8.

Ceballos, J. C. (2015). Medios de comunicación escolar, educación y ciudadania. Una mirada desde las mediaciones (Tesis de doctorado inédita). Universidad de La Plata, La Plata, Argentina.

Chamat, C. (2012). La magia de aprender. El Taller, 8, 21.

Contreras, S. (2017). La ciudadanía: una lectura en clave de Chantal Mouffe y Ernesto Laclau. Tabula Rasa, 26, 193-219. https://doi.org/10.25058/20112742.194 
Cubides, H. (1998). El problema de la ciudadanía: una aproximación desde el campo de la comunicación-educación. Nómadas, 9, 40-48. Recuperado de http://www.redalyc.org/pdf/1051/105114273005.pdf

Echeverría, R. (2003). Ontología del lenguaje. Santiago: Lom Ediciones S. A.

El Colombiano (ed.). (2012, noviembre). Prensa Escuela [Edición especial]. El Taller, 8.

El Colombiano (ed.). (2013, noviembre). Prensa Escuela [Edición especial]. El Taller, 9.

Fiori, E. (2005). Aprender a decir su palabra. El método de alfabetización del profesor Paulo Freire. En Pedagogía del oprimido (pp. 11-27). México: Siglo XXI.

Freinet, C. (1974). El diario escolar. Barcelona: Editorial Laia.

Freire, P. (1985). Pedagogía del oprimido. México: Siglo XXI.

González, C. (2016). De infarto moriremos. El Taller, 12, 12-13.

Gumucio, A. (2006, agosto). Tiempo de milagros: tres retos de la comunicación para el cambio social. Ponencia para el seminario "Sin Comunicacion no hay Pesarrollo" del Centro de Competencia en Comunicación para América Latina en Lima, Perú.

Herrón, M. (2013). Indiferencia y muerte. El Taller, 9, 19.

Kaplún, M. (2002). Una pedagogía de la comunicación (el comunicador popular). La Habana: Editorial Caminos.

Libertella, M. (2015). Entrevista a Leila Guerriero. Letras Libres, 204. Recuperado de https://www.letraslibres.com/ mexico/entrevista-leila-guerriero

Lima, P. (2012). Zarahí, emisaria del sonido y la lectura. El Taller, 8, 24.

Maiztegui, C. (2007). La participación como una opción transformadora en los procesos de educación ciudadana. Revista Electrónica Iberoamericana sobre Calidad, Eficacia y Cambio en Educación, 5(4), 2-18. Recuperado de h ttps://revistas.uam.es/index.php/reice/article/view/5529

Malagón, S. (2015, 29 de octubre). El periodismo es una forma potencial de arte: Gay Talese. Revista Semana. Recuperado de https://www.semana.com/cultura/articulo/gay-talese-el-periodismo-es-una-forma-potencial-d e-arte/448018-3

Martín-Barbero, J. (2012, febrero). El país que cabe en el periodismo. Lección inaugural de la Maestría en Periodismo de la Universidad de los Andes, Bogotá, Colombia.

Martín-Barbero, J. (2009). Culturas y comunicación globalizada. Revista Cientifica de Información y Comunicación, 6, 175-192. Recuperado de https://www.perio.unlp.edu.ar/catedras/system/files/martin_barbero_jesus__cultur as_y_comunicacion_globalizada.pdf

Martínez, M. (2002). Hermenéutica y análisis del discurso como método de investigación social. Paradigma, 23(1), 1-13. Recuperado de http://revistas.upel.edu.ve/index.php/paradigma/article/download/3049/1442+\&cd=1 $\& \mathrm{hl}=\mathrm{es} \& \mathrm{ct}=\mathrm{clnk} \& \mathrm{gl}=\mathrm{es}$

Martínez, M. (2006). La investigación cualitativa (síntesis conceptual). Revista de Investigación en Psicología, 9(1), 123-146. Recuperado de https://revistasinvestigacion.unmsm.edu.pe/index.php/psico/article/view/4033/321 3

Meléndez, E. (2012). Deporte y estudio son compatibles. El Taller, 8, 15.

Mockus, A. (2004). ¿Por qué competencias ciudadanas en Colombia? Altablero, 27, 11-12. Recuperado de https://w ww.mineducacion.gov.co/1621/article-87299.html

Nussbaum, M. (2015). Educación para el lucro, educación para la libertad. Palabras de la filósofa Martha Nussbaum al recibir el título Honoris Causa como Doctora en Filosofía, entregado por la Universidad de Antioquia en el 2015.

Perec, G. (2008). Lo infraordinario. Madrid: Impedimenta Ediciones.

Rincón, O. (2012). El periodismo según Jesús Martín-Barbero, Juan Villoro y Martín Caparrós. Revista 070. Recuperado de https://cerosetenta.uniandes.edu.co/el-periodismo-segun-jesus-martin-barbero-juan-villoro-ymartin-caparros/

Rodríguez, C. (2010). Tecnologías para nombrar almundo. Procesos de apropiación y uso de las TIC. Conferencia llevada a cabo para la Cátedra Unesco de Comunicación, Universidad de Oklahoma. 
Tascón, D. (2012). El papá de los barberos. El Taller, 8, 20-21.

Torres, T. (2013). Soledad, décima, butifarra y merecumbé. El Taller, 9, 14-15.

Valderrama, C. (2007). Ciudadania y comunicación. Saberes, opiniones y haceres escolares. Bogotá: Siglo del Hombre Editores.

Villoro, J. (2012, 10 de agosto). El ornitorrinco de la prosa. Tres reflexiones que definen poéticamente la crónica periodística. La Nación. Recuperado de https://www.lanacion.com.ar/cultura/el-ornitorrinco-de-la-prosa-nid 1497616

\section{Notas}

* Artículo de investigación científica.Este artículo es fruto de la investigación "La mediación de Prensa Escuela en la formación ciudadana y la ética”, ejecutada en alianza entre la Universidad Pontificia Bolivariana, la Universidad de San Buenaventura con su grupo de investigación ESINED y el periódico El Colombiano de Medellín, dentro del Programa Prensa Escuela.

\section{Licencia Creative Commons CC BY 4.0}

Cómo citar este artículo: Campuzano Baena, C., y Guerrero Cabrera, S. A. (2019). La narración periodística como estrategia de formación ciudadana en Prensa Escuela. Signo y Pensamiento, 38(75). https://doi.org/1 0.11144/Javeriana.syp38-75.npef 